\title{
13 tendencias de la cooperación internacional sobre agua saneamiento
}

\author{
Gladys Elizabeth Menjivar \\ David Alexander Figueroa
}

\section{INTRODUCCIÓN}

El agua es esencial para la vida humana, para la salud básica y para la supervivencia, así como para la producción de alimentos y para las actividades económicas, no obstante, el agua dulce representa tan solo el 3\% de los recursos hídricos del planeta y el $70 \%$ de esa proporción se encuentra atrapada en glaciares e icebergs por 10 que no se dispone de ella para el consumo humano, sin embargo, estamos ahora enfrentado una emergencia global en la cual más de mil millones de personas carecen de acceso al suministro básico de agua potable y más de dos mil millones no tienen acceso a un saneamiento adecuado, que es la causa primaria de enfermedades relacionadas con el agua, $\mathrm{H}$ onduras no es la excepción pues gran cantidad de la población todavía no accesa a estos servicios.

El presente documento tien e como propósito describir la situación del agua y saneamiento en el contexto internacional y nacional, así mismo se hace referencia a todas las cumbres y conferencias internacionales relacionadas con el agua ya que ésta ha sido una preocupación internacional desde la década de los setenta. También se resalta la cooperación internacional en el ámbito multilateral, bilateral y de país pues las mejoras y avances en estos sectores se debe en gran medida a los distintos cooperantes.

\section{CONFERENCIAS Y CUMBRES INTERNACIONALES SOBRE EL AGUA}

La creciente convicción de que el agua es cada vez más un recurso escaso, tanto en cantidad como en calidad, ha motivado a la comunidad internacional a celebrar varios foros en los que se trataría este problema para encontrar soluciones gl obales. D esde los años 70 aproximadamente se viene entonces organizando eventos que discuten - directa o indirectamente - el problema mundial del agua para intentar encontrarle soluciones.
La preocupación sobre el tema se acrecentó durante los últimos años y esto motivó que en 1996 se organicen dos entidades mundiales en torno al tema del agua: el $C$ onsejo $M$ undial del $A$ gua (W W C) y la A sociación M undial del A gua (GW P). El WW C instituyó la realización de Foros $M$ undiales sobre el A gua, como un espacio de discusión y propuesta y en 1997 se realizó el primero de ellos en $M$ arrakech, M arruecos. En este evento se encomienda al WW C trabajar en la Visión Global sobre el A gua y el A mbiente para el Siglo XXI, que fue final mente presentada en el Segundo Foro $M$ undial realizado en La $H$ aya, $\mathrm{H}$ olanda en el 2000. Basándose en el documento presentado en La $\mathrm{H}$ aya se espera lograr el planteamiento de acciones concretas por los países en el próximo Foro M undial del A gua que se realizó en marzo del presente año (2003) en Kyoto Japón.

En el cuadro N o. 1 se detallan las principales reuniones internacionales realizadas desde los años 70's hasta la actualidad (incluyendo al gunas que están programadas para el futuro) en las que se trató la temática del agua de forma directa o entre otros temas más generales.

Del análisis de los temas de estas reuniones se puede decir que puede haber un cambio en el enfoque bajo el que se les consideró, así se pasa del énfasis en el mejoramiento de la provisión de agua potable y saneamiento básico que fue el tema principal desde los años $70^{\prime}$ a los 90' (Década internacional del A gua Potable y el Saneamiento 1981 - 1990); a una mayor preocupación por la gestión en si con énfasis en cuestiones ambientales y la preservación del agua como parte de los sistemas ecológicos, enfatizándose por lo tanto su uso sostenible, a partir de la Conferencia de Dublín y la C umbre de la Tierra en 1992 (www.aguabolivia.org/situacionaguaxvisionmundial). 


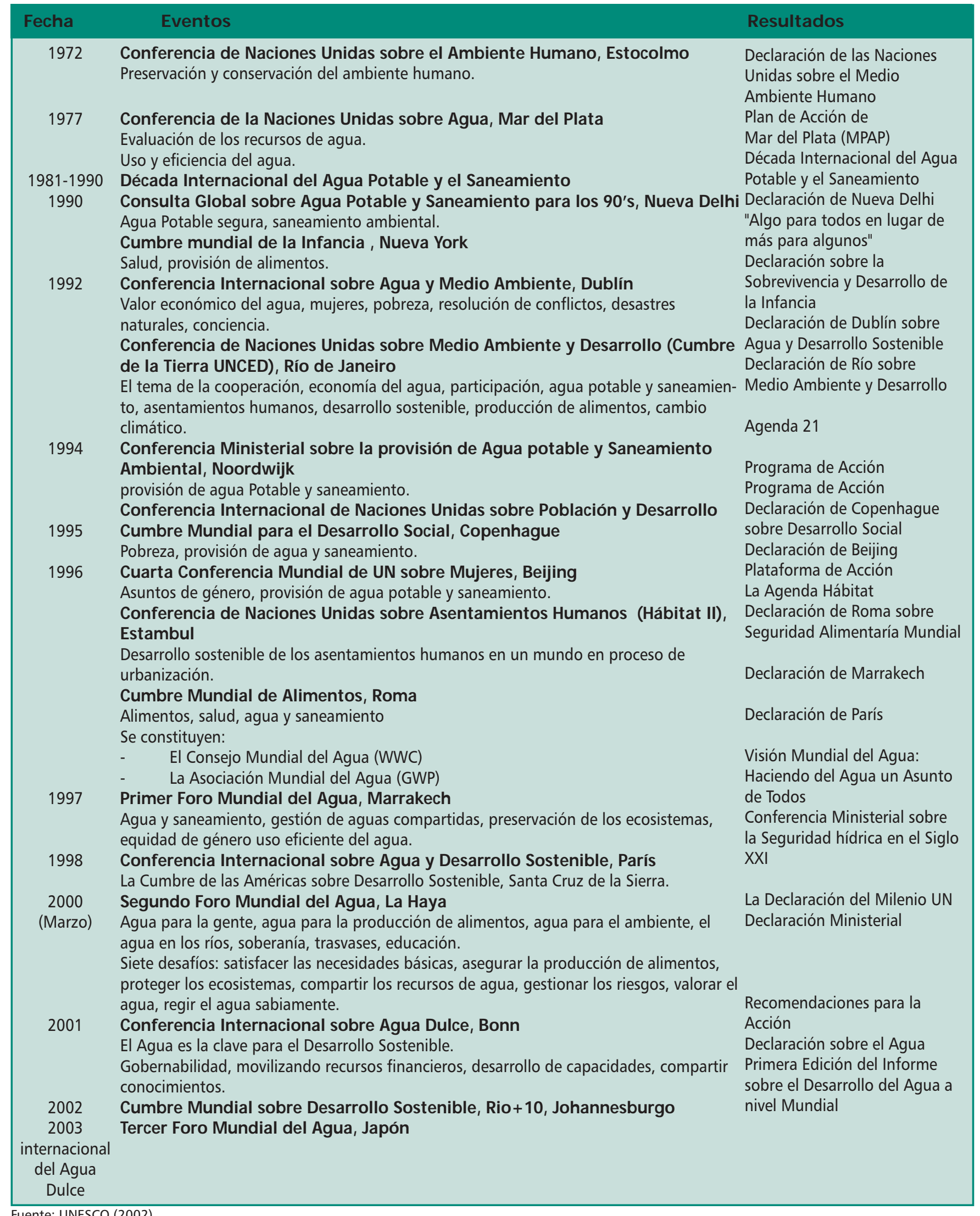

Fuente: UNESCO (2002) 
Del análisis de los temas de estas reuniones se puede decir que puede haber un cambio en el enfoque bajo el que se les consideró, así se pasa del énfasis en el mejoramiento de la provisión de agua potable y saneamiento básico que fue el tema principal desde los años 70' a los 90' (D écada internacional del A gua Potable y el Saneamiento
1981 - 1990); a una mayor preocupación por la gestión en sí con énfasis en cuestiones ambientales y la preservación del agua como parte de los sistemas ecológicos, enfatizándose por lo tanto su uso sostenible, a partir de la Conferencia de Dublín y la C umbre de la Tierra en 1992 (www.aguabolivia.org/situacionaguaxvisionmundial).

Cuadro No. 2. Principales Reuniones internacionales sobre el Agua

\begin{tabular}{|c|c|c|c|}
\hline Evento & Lugar y Fecha & \multicolumn{2}{|c|}{ Contenido } \\
\hline $\begin{array}{l}\text { Conferencia } \\
\text { Internacional } \\
\text { sobre el Agua y el } \\
\text { Medio Ambiente: } \\
\text { El Desarrollo en la } \\
\text { Perspectiva del } \\
\text { Siglo XXI }\end{array}$ & $\begin{array}{l}\text { Dublín, Irlanda, } 26 \text { al } 31 \text { de } \\
\text { enero de } 1992\end{array}$ & $\begin{array}{l}\text { - Plan de Acción: } \\
\text { - Evaluación de los recursos } \\
\text { - Eficiencia en la utilización } \\
\text { - Medio Ambiente y lucha } \\
\text { - Políticas, planificación y o } \\
\text { - Riesgos naturales } \\
\text { - Información pública: educ } \\
\text { - Cooperación regional } \\
\text { - Cooperación internaciona } \\
\text { Declaración de Dublín sobre } \\
\text { el Agua y el Desarrollo Sos- } \\
\text { tenible } \\
\text { Principios rectores } \\
\text { El agua dulce es un recurso } \\
\text { finito y vulnerable, impres- } \\
\text { cindible para el manteni- } \\
\text { miento de la vida, el desa- } \\
\text { rrollo y el medio ambiente. } \\
\text { El desarrollo y la ordenación } \\
\text { de los recursos hídricos de- } \\
\text { berán basarse en un criterio } \\
\text { participativo, al que contri- } \\
\text { buyan todos los usuarios, } \\
\text { planificadores y autoridades } \\
\text { responsables. } \\
\text { La mujer desempeña un } \\
\text { papel central en el aprovi- } \\
\text { sionamiento, administra- } \\
\text { ción y protección del agua. } \\
\text { El agua tiene un valor } \\
\text { económico en todos los } \\
\text { usos competitivos que se } \\
\text { hacen de ella y deberá } \\
\text { recomo un bien }\end{array}$ & $\begin{array}{l}\text { í́dricos } \\
\text { el Agua } \\
\text { ntra la contaminación } \\
\text { lenación } \\
\text { ción, capacitación e investigación } \\
\text { Programa de Acción } \\
\text { - Mitigación de la pobreza y de las } \\
\text { enfermedades Protección contra } \\
\text { los desastres naturales } \\
\text { - Conservación y } \\
\text { reaprovechamiento del agua } \\
\text { - Desarrollo urbano sostenible } \\
\text { - La producción agrícola y el } \\
\text { abastecimiento del agua en el } \\
\text { medio rural } \\
\text { - Protección del ecosistema } \\
\text { acuático } \\
\text { - Solución de conflictos derivados } \\
\text { - } \text { del agua medio ambiente favorable } \\
\text { - Ca base de conocimientos de capacidades }\end{array}$ \\
\hline
\end{tabular}




\begin{tabular}{|c|c|c|}
\hline Evento & Lugar y Fecha & Contenido \\
\hline $\begin{array}{l}\text { Conferencia de las } \\
\text { Naciones Unidas } \\
\text { sobre el Medio } \\
\text { Ambiente y el } \\
\text { Desarrollo }\end{array}$ & $\begin{array}{l}\text { Rio de Janeiro, Brasil, } 3 \text { al } \\
14 \text { de junio de } 1992\end{array}$ & $\begin{array}{l}\text { Capítulo } 18 \text { "Protección de la calidad y el suministro de los recursos de agua } \\
\text { dulce: aplicación de criterios integrados para el aprovechamiento, ordena- } \\
\text { ción y uso de los recursos de agua dulce" } \\
\text { - Ordenación y aprovechamiento integrados de los recursos hídricos } \\
\text { - Evaluación de los recursos hídricos. } \\
\text { - Protección de los recursos hídricos, la calidad del agua y los ecosistemas } \\
\text { acuáticos. } \\
\text { - } \quad \text { Abastecimiento de agua potable y saneamiento. } \\
\text { - El agua y el desarrollo urbano sostenible. } \\
\text { - } \quad \text { Agua para la producción sostenible de alimentos y el desarrollo rural } \\
\text { sostenible. }\end{array}$ \\
\hline $\begin{array}{l}\text { Conferencia } \\
\text { Internacional } \\
\text { sobre Agua y } \\
\text { Desarrollo } \\
\text { Sostenible }\end{array}$ & $\begin{array}{l}\text { París, Francia, } 19 \text { al } 21 \text { de } \\
\text { marzo de } 1998\end{array}$ & $\begin{array}{l}\text { - Declaración de París } \\
\text { - Programa de Acciones Prioritarias } \\
\text { - } \text { gejorar el conocimiento de los recursos hídricos y de los usos para una } \\
\text { - Favorecer el desarrollo de las capacidades institucionales y humanas } \\
\text { - Definir las estrategias para una gestión sostenible del agua e identificar } \\
\text { los medios de financiación apropiados } \\
\text { Anexo: Promoción de la asociación y de la concentración }\end{array}$ \\
\hline $\begin{array}{l}\text { Dublín }+10 \text {, } \\
\text { Conferencia sobre } \\
\text { Agua Dulce } \\
\text { "Agua, una de las }\end{array}$ & $\begin{array}{l}\text { Bonn Alemania Diciembre } \\
\text { del } 2001\end{array}$ & $\begin{array}{l}\text { Las claves se establecieron como: } \\
\text { 1. La primera clave es satisfacer las necesidades de agua segura de los } \\
\text { pobres. } \\
\text { 2. Descentralización es la clave. El nivel local es donde la política nacional } \\
\text { logra satisfacer las necesidades de la comunidad. } \\
\text { 3. La clave para un mejor alcance (outreach) son las nuevas asociaciones. } \\
\text { 4. La clave para una armonía a largo plazo con la naturaleza y la vecindad } \\
\text { (neibourgh) son los acuerdos cooperativos a nivel de la cuenca } \\
\text { hidrográfica, incluyendo el agua across water that touch many shores. } \\
\text { 5. La clave esencial es una gobernabilidad más fuerte y con mejor desempe- } \\
\text { ño }\end{array}$ \\
\hline Río + 10 & $\begin{array}{l}\text { Johannesburgo, Sud } \\
\text { África Agosto - Septiem- } \\
\text { bre del } 2002\end{array}$ & $\begin{array}{l}\text { Gestión del recurso natural base } \\
\text { Agua } \\
\text { Desarrollar la gestión integrada de los recursos de agua y planes de } \\
\text { eficiencia del agua hasta el } 2005 \\
\text { Agua y Saneamiento } \\
\text { Hasta el año } 2015 \text { reducir a la mitad Halve, la proporción de personas sin } \\
\text { acceso a agua potable segura (reafirmación de las Metas de Desarrollo del } \\
\text { Milenio)[1] } \\
\text { Hasta el año 2015, reducir a la mitad la proporción de personas que no } \\
\text { tienen acceso al saneamiento básico. } \\
\text { Entre los compromisos que se establecieron para la ocasión: } \\
\text { - Los Estados Unidos anunció la inversión de más de } 970 \$ \text { millones de } \\
\text { dólares en los próximos tres años en proyectos de agua y saneamiento. } \\
\text { - La Unión Europea anunció la iniciativa de "Agua para la Vida" que busca } \\
\text { comprometer a las contrapartes en alcanzar las metas sobre agua y } \\
\text { saneamiento, prioritariamente en África y Asia Central. } \\
\text { - El Banco Asiático para el Desarrollo, otorgó un crédito de } 5 \$ \text { millones a } \\
\text { Hábitat de las Naciones Unidas y } 500 \$ \text { millones de crédito de rápida } \\
\text { disponibilidad para el Programa de Agua para ciudades Asiáticas. } \\
\text { o Las Naciones Unidas ha recibido } 21 \text { otras iniciativas sobre agua y sanea- } \\
\text { miento con al menos } 20 \$ \text { millones de recursos extra. }\end{array}$ \\
\hline
\end{tabular}

Fuente: CEPAL, Recomendaciones de las Reuniones internacionales sobre el Agua: de Mar de Plata a París, División de Medio Ambiente y Desarrollo, mimeo, Distr. Restringida Octubre 1998 


\section{SITUACIÓN AGUA, SANEAMIENTO EN HONDURAS}

En 1990, la población de H onduras era de 4.8 millones de habitantes de los cuales $60.5 \%$ pertenecían al área rural y el $39.5 \%$ en el área urbana; en la actualidad la población asciende a 6,535,344 habitantes de los cuales $44.8 \%$ corresponde al área urbana mientras un 55.2\% al área rural (Encuesta, 1993:1; IN E, C enso 2001 :2)

Según el C enso de 1988 y datos preliminares del C enso 2001, las infecciones intestinales son la primera causa de mortalidad infantil y la segunda causa de la morbilidad y mortalidad general. Las enfermedades diarréicas bacterianas y parasitarias, tienen como medio de transmisión principal la contaminación del agua para el consumo humano y preparación de los alimentos, debido a la defecación al aire libre, la disposición inadecuada de las excretas y falta de tratamiento de las aguas negras de los al cantarillados (Encuesta, 1993 :1; IN E 2,001).

\section{SU BSECTOR DE AGUA Y SANEAMIENTO}

En nuestro país existe un subsector de agua y saneamiento el cual está constituido por entidades públicas y privadas que tienen la responsabilidad de ofrecer a la población los sistemas y servicios adecuados, estas entidades son: Servicio A utónomo $\mathrm{N}$ acional de A cueductos y A Icantarillados (SA N A A ) constituye la principal institución responsable por la provisión y financiamiento de los servicios de agua y alcantarillados.

\section{- Servicio de Acueductos y A lcantarillados (SANAA)}

A ctúa en poblaciones urbanas y en comunidades rural es de más de 200 habitantes favorecidas mediante financiamiento externo, a través de organismos como: Banco Interamericano de Desarrollo (BID), Banco M undial (BM ), G obierno A lemán, G obierno Suizo, A gencia Internacional para el Desarrollo (U SA ID) entre otras (Encuesta Sobre U so, 0 peración y M antenimiento de Letrinas 1993:2). A ctualmente tiene la administración directa de 63 sistemas de agua potable en 15 comunidades urbanas grandes, 47 comunidades pequeñas urbanas y rural es, y tiene a su cargo el sistema de al cantarillado de Tegucigal pa, administra en forma indirecta a través de juntas de agua, otros 751 sistemas de abastecimiento de agua. A partir de 1991 el SA N A A ha incrementado su inversión en el área rural pasando de un promedio de $15 \%$ en los años $1989-90$ a $40 \%$ en los años 1991-92 ( Plan de A cción N acional, 1995 :97).

\section{- Secretaría de Salud Pública}

La Secretaría de Salud Pública, concede prioridad a la población rural no favorecida por el SA N A A, por lo que estas dos organizaciones deben trabajar conjuntamente, con las municipalidades, Secretarías de Estado y otras instituciones afines con los objetivos promociónales de salud. Las actividades de la Secretaría de Salud
Pública forman parte de un programa de salud integral con fuerte participación comunitaria en todas las etapas de implementación de los sistemas de abastecimiento de agua ( pozos y acueductos) y disposición de excretas (letrinas y fosas sépticas).

\section{- Las municipalidades, patronatos y juntas administrado- ras de agua y saneamiento.}

D e las 298 municipalidades de todo el país 100 administran sus propios sistemas de abastecimiento de agua y 54 gestionan el sistema de alcantarillado. Entre las principales se destaca la municipalidad de San Pedro Sula que a través de su División M unicipal de A guas (DIM A ), proporciona los servicios de agua potable a la población de esa ciudad y de los municipios y al deas circunvecinas; la municipalidad de N ueva O cotepeque, Santa Rosa de Copán y Puerto Cortés, San Lorenzo y Choluteca también han creado divisiones similares para brindar estos y otros servicios.

U no de los problemas de la mayoría de las municipalidades es que no están adecuadamente organizadas, ni capacitadas para administrar los sistemas de agua y saneamiento.

\section{- Organizaciones Privadas de Desarrollo y las No Guber- namentales (OPDs y ONGs) y Empresas Privadas Comercializadoras de Agua.}

Las agencias de ayuda externa y las O PD s que también juegan un papel importante en el desarrollo del sector, por lo general operan asociadas a instituciones locales, siguien do los lineamientos del SA N A A y Secretaría de Salud Pública; mediante acuerdos con estos organismos.

Las O PD sque actúan en el sector, son alrededor de 20, reciben apoyo financiero de organismos externos para los cual es operan como agencias ejecutoras. 0 tras poseen recurso financiero y operan en forma independiente.

Este subsector está ubicado dentro del sector salud, el cual ha definido su política y establecido lineamientos para las instituciones que ejecutan programas y proyectos al respecto ( Plan de A cción N acional, 1995 :97; Encuesta 1993 :1,2 ; H acia la Transformación N acional, 2002: 18).

\section{Contexto del Servicio de Agua en H onduras}

Datos brindados por los Censos H onduras 1974, 1988 y 2001, y diferentes encuestas entre ellas la de Epidemiología y Salud Familiar (EN ESF) y la Encuesta Permanentes de H ogares (EPH PM ) proporcionan información más detallada sobre la situación de agua en $\mathrm{H}$ onduras. 
Gráfico No. 1. Población con y sin acceso al servicio de Agua, Honduras, 1974, 1992,1988 y 2001

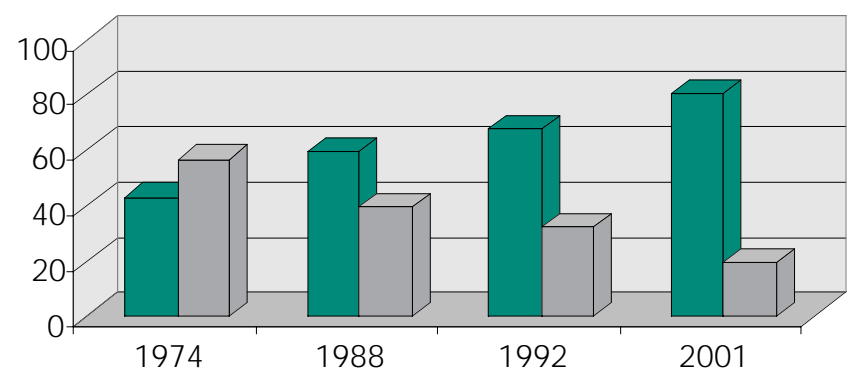

\section{$\square$ Con Acceso \\ Sin Acceso}

Fuente: Elaboración propia, con datos proporcionados por la Secretaría de Salud Pública, ENESF 1992 y Base de Datos Redatam INE, 2001.

Según el censo de 1974 el porcentaje de la población con acceso al servicio de agua ascendió a $43.15 \%$, el censo 1988 refleja un porcentaje de $62.08 \%$ y la EN ESF 92 un 68.1\%; en el último censo poblacional y de vivienda 2001 se observa un aumento significativo, siendo el porcentaje $80.66 \%$ la población con acceso a dicho servicio. (Situación A ctual del Sector A gua y Saneamiento en H onduras:17; IN E, 2001 ). Si comparamos los datos del censo de 1974, 1988 y los del 2001 se ve que el país ha mejorado significativamente y que las coberturas del servicio de agua se han ido incrementando considerablemente.

Se considera con acceso a servicio de agua aquellas familias que posean al gunas de estas opciones:

a. Con tubería dentro de la vivienda o dentro de la propiedad (conexión domiciliaria).

b. Con tubería fuera de la propiedad a más de $100 \mathrm{mts}$., con tubería a más de $100 \mathrm{mts}$. Si es un sistema público y pozos con bomba manual o eléctrica (fácil acceso) (C ondiciones de A gua y Saneamiento en Honduras 1990-1995: 15).

La población del área urbana es la que presenta mayor acceso al servicio de agua en relación al área rural con un $92.46 \%$ y $70.64 \%$ respectivamente. Por consiguiente en el año 2001 la población rural tiene menos acceso al servicio en comparación con la urbana.

A nivel urbano llama la atención Tegucigalpa con el porcentaje de hogares de cobertura de agua con servicio de agua bajo, que apenas alcanza el $75 \%$, sin embargo, es el dominio que presenta la mayor proporción de hogares que poseen agua dentro de la vivienda $39 \%$. San Pedro Sula y ciudades medianas presentan el más alto índice de cobertura, con un $96 \%$ del cual un $71.3 \%$ posee servicio fuera de la vivienda pero dentro de la propiedad.

En las zonas rurales se destaca la de occidente con apenas un
$57 \%$ de la población cubierta con servicios de agua, seguido de la zona rural sur con $61 \%$, lo que indica que la inversión en este rubro debería focalizarse con especial énfasis en la zona rural occidente y sur del país. (Condiciones de A gua y Saneamiento en Honduras, 1990-1995: 17-19).

De acuerdo al cuadro N o. 3, el agua de las viviendas en $\mathrm{H}$ onduras proviene en mayor porcentaje de tuberías del sistema público y privado (73\%), pero llama también la atención el porcentaje que ocupa la obtención de éste vital líquido a través de vertientes, ríos y arroyos (12.36\%) lo cual debe llamar a la reflexión sobre el cuidado y prevención de dichos sitios. Otro aspecto relevante es el incremento de vendedores o repartidores ambulantes de agua principalmente en las zonas urbanas marginales donde se hace casi imposible el suministro del servicio de agua por medio de tuberías.

En nuestro país los departamentos que su población cuenta con mayor acceso al servicio de agua son: C ortés $91.76 \%$, Islas de la Bahía 89.31\%, A tlántida 85.90\%, Yoro 84.87\% y Francisco M orazán con una cobertura de $84.05 \%$.

M ientras los departamentos que su población cuenta con menos acceso del servicio de agua son: G racias a Dios 47.70\%, El Paraíso $35.75 \%$, O lancho $31.25 \%$, Intibuca $30.83 \%$, La Paz $28 \%$ y Lempira $26.57 \%$.

En $\mathrm{H}$ onduras el consumo de agua anualmente por persona asciende a 14,949 metros cúbicos (A gua y Desarrollo Sustentable, 2003).

Según proyecciones del Banco M undial actual mente la cobertura de agua potable en el país asciende a 86\%, para el año 2005 se estima que será de $90 \%$ y para el 2015 se espera lograr un 95\% ( H acia la Transformación N acional, 2002 :18).

Los resultados reflejan que el $34.57 \%$ de la población tenía acueducto con tubería dentro de la vivienda, un $45.83 \%$ el abastecimiento le llegaba fuera de la vivienda pero dentro de su propiedad y el $19.6 \%$ restante no contaba con instal aciones de tubería por lo que

Cuadro No. 3. De donde le proviene el Agua a las Viviendas, Honduras, 2001

\begin{tabular}{|lrr|}
\hline Categorías & Viviendas & $\%$ \\
\hline De tubería del sist. Público y Privado & 871545 & 73.59 \\
De pozo malacate & 46062 & 3.89 \\
De pozo con bomba & 51086 & 4.31 \\
De vertiente, rio o arroyo & 146342 & 12.36 \\
De lago o laguna & 2605 & 0.22 \\
De vendedor o repartidor ambulante & 22675 & 1.91 \\
Otro & 44009 & 3.72 \\
Total & 1184324 & 100.00 \\
\hline
\end{tabular}

Fuente: Instituto Nacional de Estadísticas, Honduras C.A. Censo de población y vivienda 2001.Procesado con Redatam G4 
Gráfico No. 2. Población con y sin Acceso al servicio de Agua, por departamento, Honduras 2001

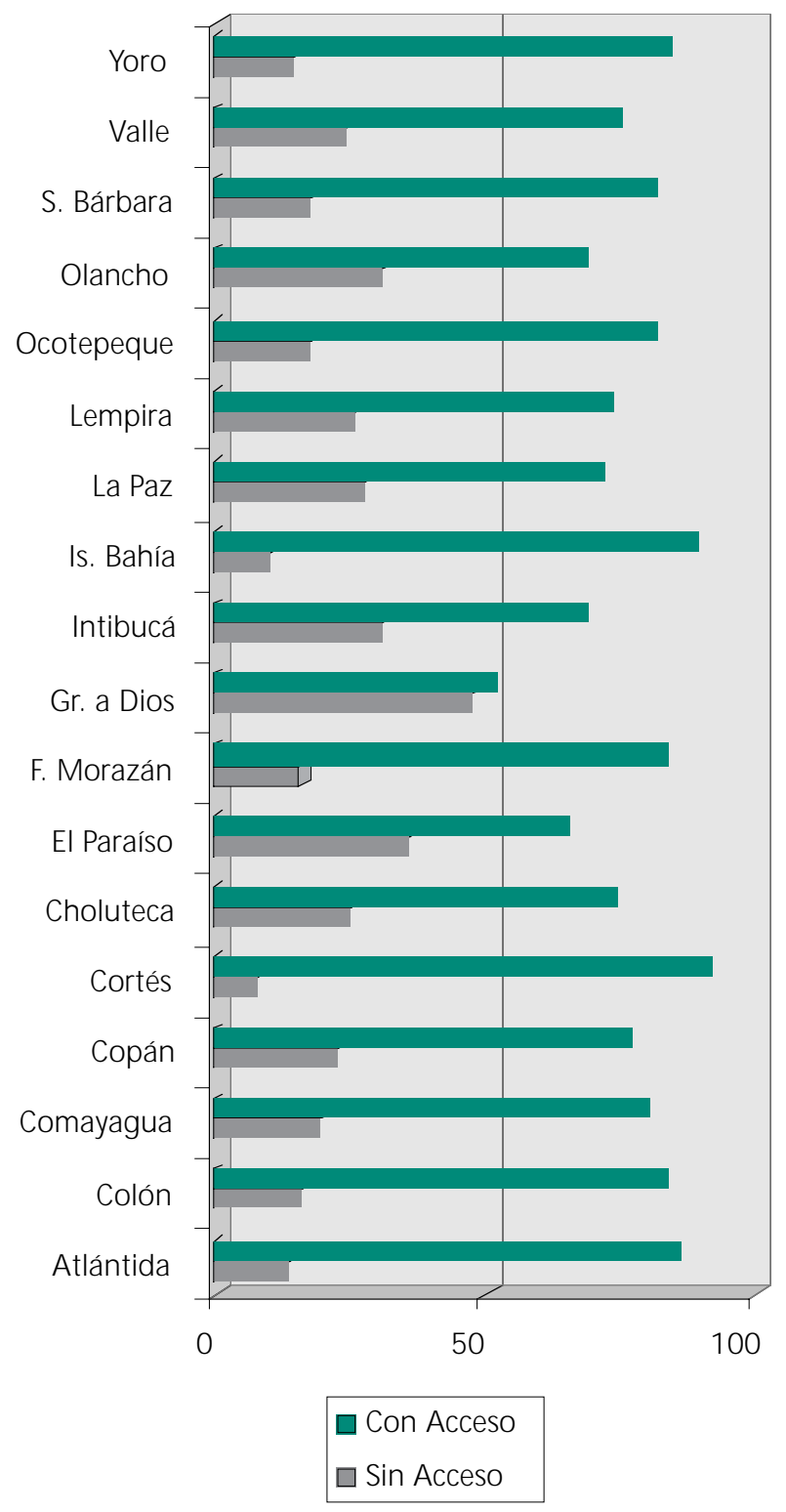

Fuente: Elaboración propia basada en datos obtenidos del Instituto Nacional de Estadística, Honduras C.A. Censo de población y vivienda 2001. Procesado con Redatam G4.

utilizaba otras fuentes de abastecimiento, como pilas públicas, agua no potabilizada proveniente de pozos, arroyos, camiones y tanques, la cual comúnmente está contaminada, lo que afecta a la población, especialmente infantil.

\section{Contexto del Servicio de Saneamiento en H onduras}

Cuando no existe o no son suficientes los sistemas de saneamiento básico, el agua es el mayor peligro para la salud humana, debido a la falta de tratamiento del vital liquido, inadecuada disposición de excretas y desperdicios sólidos.

En nuestro país los servicios de saneamiento han mejorado considerablemente ya que la población cubierta con dicho servicio pasó de $32.16 \%$ en 1974 a $58.81 \%$ en 1988 sien do éste el período de mayor aumento, posteriormente se incrementó a $64.4 \%$ en 1992 y para el 2001 la cifra ascendió a 66.90\% (Situación A ctual del Sector A gua y Saneamiento, 1997 :17; IN E, Base de Datos, 2001).

En saneamiento la cobertura global deseada de $79 \%$ según el Plan de Desarrollo de 1983 para ejecutarse en 1990 alcanzó a 61.5\% o sea 2.9 millones de hondureños con acceso a este servicio básico de los cuales $60 \%$ pertenecían al área urbana, por lo que al rededor de 832,000 personas dejaron de beneficiarse con el servicio. Como resultado $\mathrm{H}$ onduras registraba en 1990 un contingente poblacional de 1.8 millones ( 38.5 del total de la población) sin disponibilidad de servicio de saneamiento básico.

En el periodo 1990- 1992 se han incorporado aproximadamente 314,000 personas al servicio, lo que equivale a una tasa de crecimiento anual de $5.2 \%$ o a un promedio de 157,000 personas anualmente. Si esta tasa de incremento se mantiene hasta 1995, $3.7 \mathrm{mi}-$ Ilones de personas tendrían acceso al servicio de saneamiento, lo que implica que la meta de dar cobertura a 4,260,000 hondureños (78\% de la población) no podría ser alcanzado quedando al rededor de 500,000 personas desaten didas

Se consideran con acceso al servicio de saneamiento aquellas familias que poseen inodoro conectado a la red de alcantarillado 0 a un pozo séptico y letrinas de cierre hidráulico, abonera y de pozo simple (otros medios) (Plan de A cción N acional, 1995: 99,100).

Gráfico No. 3. Población con y sin acceso al servicio de Saneamiento, Honduras, 1974, 1992,1988 y 2001

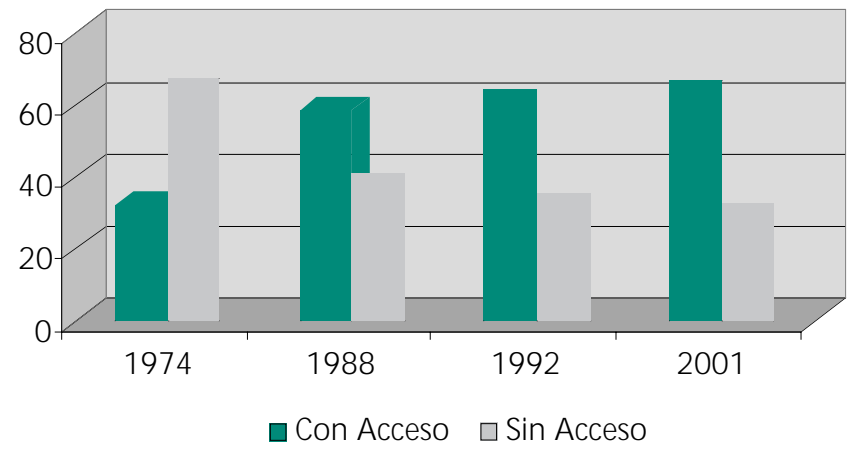

Fuente: Elaboración propia, con datos proporcionados por la Secretaría de Salud Pública, ENESF 1992 y Base de Datos Redatam INE, 2001. 
La población del área urbana es la que presenta mayor acceso al servicio de saneamiento en relación al área rural con un $72.72 \%$ y $61.97 \%$ respectivamente. Por consiguiente en el año 2001, la población rural tiene menos acceso al servicio en comparación con la urbana.

La mayor parte de la población del país sin acceso al servicio de san eamiento se concentra en las zonas rural es y en las zonas urbanas marginales de Tegucigal pa y San Pedro Sula.

En Honduras $28.17 \%$ de las viviendas cuenta con inodoros conectadosa la red de al cantarillado y $22.71 \%$ está conectado a pozo séptico y una minoría los descarga a ríoso quebradas (1.66\%); mientras las viviendas que cuentan con letrinas de pozo representan el $25.28 \%$. También cabe mencionar el alto porcentaje en el país de las viviendas que no cuentan con servicio sanitario siendo de $22.18 \%$.

\section{Cuadro No. 4. Servicio Sanitario en Viviendas Honduras 2001}

$\begin{array}{lr}\text { Inodoro conectado a red alcantarillado } & 28.17 \% \\ \text { Inodoro conectado pozo séptico } & 22.71 \% \\ \text { Inodoro con descarga a río, quebrada } & 1.66 \% \\ \text { Letrina de pozo } & 25.28 \% \\ \text { No tiene } & 22.18 \% \\ \text { Total } & 100.00 \%\end{array}$

Fuente: Instituto Nacional de Estadísticas, Honduras C.A. Censo de población y vivienda 2001. Procesado con Redatam G4

La mayoría de los hogares ubicados en el área urbana poseen ya sea inodoro o letrina, sin embargo, el porcentaje de los que no tiene ningún tipo de servicio sanitario es aún bastante alto, por lo que no debemos hablar de condiciones de san eamiento totalmente aceptable para esta zona. Las condiciones de insalubridad son todavía más lamentables en el área rural donde al rededor del $36 \%$ de los hogares para 1994 no tenían servicio sanitario (Condiciones de A gua y Saneamiento, 1990-1995: 26, 27).

En nuestro país los departamentos que su población cuenta con mayor acceso al servicio de saneamiento son: C ortés $84.13 \% \%$, Islas de la Bahía $83.30 \%$, A tlántida $74.11 \%$, Francisco M orazán $71.25 \%$ y Yoro con una cobertura de $70.63 \%$.

M ientras los departamentos que su población cuenta con menos acceso del servicio de saneamiento son: $\mathrm{G}$ racias a D ios $72.32 \%$, Valle $52.27 \%$, Lempira $48.07 \%$, Olancho $46.74 \%$ y Choluteca $42.54 \%$.

Según proyecciones del Banco M undial actualmente la cobertura nacional en el servicio de saneamiento es de $73.0 \%$, para el año 2005 se estima que será de $75 \%$ y para el 2015 se espera lograr un 95\% (H acia la Transformación N acional, 2002 :18).
Gráfico No. 4. Población con y sin Acceso al servicio de Saneamiento, por departamento, Honduras, 2001

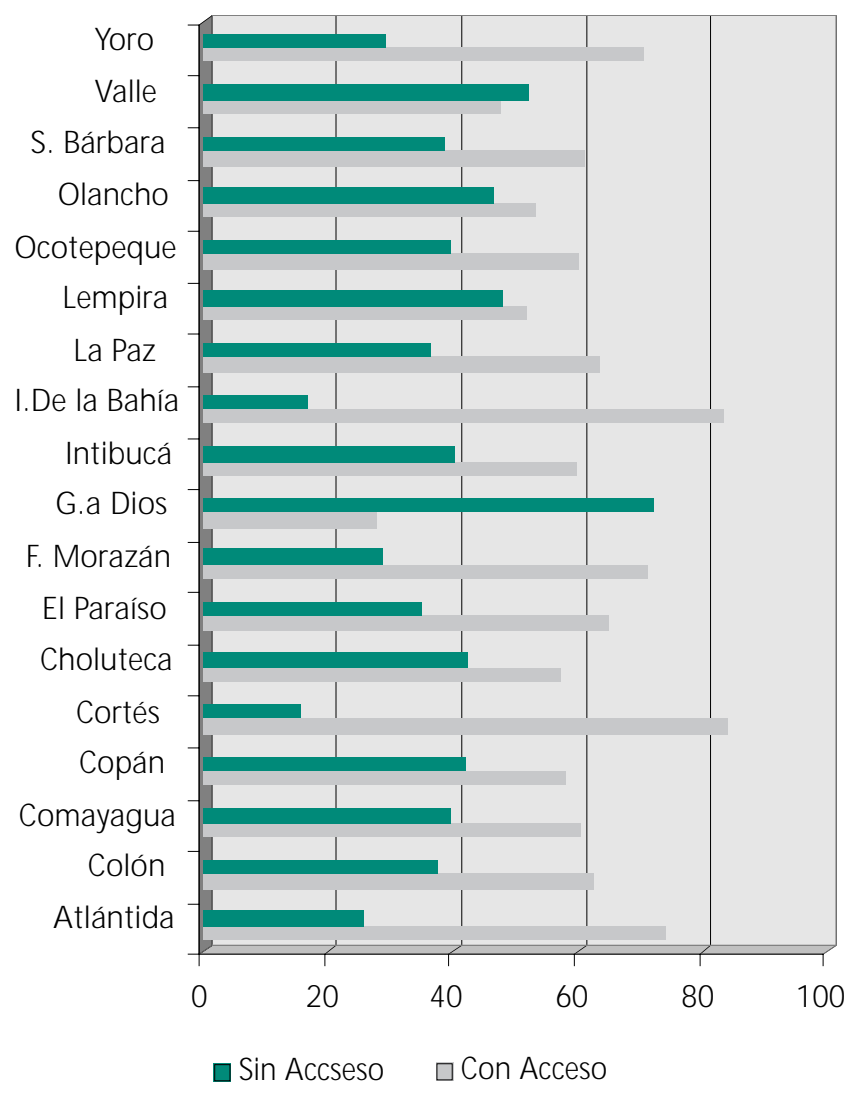

Fuente: Elaboración propia basada en datos obtenidos del Instituto Nacional de Estadísticas, Honduras C.A. Censo de población y vivienda 2001.Procesado con Redatam G4.

\section{HONDURAS Y LA COOPERACION INTERNACIONAL.}

H onduras presentó a la comunidad internacional reunida en Estocolmo, el plan maestro de reconstrucción y transformación nacional- PM RT N -, en mayo de 1999.- Este plan describía la magnitud de los daños causados por el huracán mitch y el en orme reto para la reconstrucción y transformación del país.- La comunidad donante brinda cooperación a través de financiamiento reembolsable y no reembolsable.

Los rubros resultantes de la cooperación internacional son:

Cooperación Bilateral: predominantemente en la ayuda de A lemania, Bél gica, C anadá, España, EstadosU nidos, Finlandia, Francia, H olanda, Italia, Japón, Reino U nido, Suecia, suiza, y la U nión Europea.

Cooperación multilateral provista por el Banco M undial, Banco Interamericano de Desarrollo, Banco C entroamericano de Integración Económica, Fondo Internacional para el D esarrollo A grícola y el Fondo M onetario Internacional. 
A sistencia técnica: proporcionada por A rgentina, Brasil, Chile, Colombia, y M éxico.

\section{COOPERACION BILATERAL}

La cooperación al emana en $\mathrm{H}$ onduras se centra en varioscampos: Iucha contra la pobreza, desarrollo rural, protección del medio ambiente, fortal ecimiento del sistema educativo, fomento de la pequeña y mediana industria para la generación de empleo, seguridad alimentaria, y sobre to do "mejoramiento de la salud reproductiva, así como la prevención y control del VIH-SIDA" . La distribución financiera para el sector salud y nutrición es de 5,560 mil dólares(PNU D, 2001: 13,15).

En el caso de Bélgica, la cooperación se centra en cinco sectores: "salud y planificación familiar", educación y capacitación, agricultura y seguridad alimentaria y desarrollo comunitario.- Los fondos belgas estimados para $\mathrm{H}$ onduras durante el periodo 1998-2000, fueron de 937,975.49 dólares. (PNUD,2001: 16).

El gobierno canadien se centra su asistencia en seis áreas prioritarias: necesi dades básicas humanas, proveer asistencia en salud, educación básica, planificación familiar, nutrición , agua y saneamiento, participación de la mujer en el desarrollo, servicios de infraestructura, derechos humanos, democracia, desarrollo del sector privado y medio ambiente.

EI A CDI (A gencia C anadiense para el Desarrollo Internacional) ha trabajado por más de 30 años en $\mathrm{H}$ onduras tanto a nivel de proyectos como a nivel de políticas.- La distribución financiera estimada para el sector salud asciende a 51746 mil dólares( PN U D, 2001 $: 18,19)$.

La A gencia de Cooperación Española ha optado por concentrar la cooperación en los si guientes sectores: gobernabilidad y fortalecimiento institucional, salud y servicios sociales básicos, educación y vivienda.- La distribución financiera estimada para el sector salud es de 1,924 mil dólares. (PNU D,2001 : 20,21 ).

A nivel de política el gobierno de los Estados U nidos de A mérica, a través del U SA ID (A gencia para el Desarrollo Internacional de los Estados U nidos de A mérica), apoya en $\mathrm{H}$ onduras las siguientes áreas de interés: desarrollo de la agricultura, democracia y gobernabilidad, educación y capacitación, "salud", sostenibilidad del medio ambiente, asistencia en situaciones de emergencia causada por desastres natural es y guerras y desarrollo municipal.

La cooperación financiera Estadounidense en total es de 7491 151 mil dólares, de los cuales 281, 940 mil corresponden al sector salud, representando el $37.63 \%$ de la cooperación para el período 1986-2004 ( PNUD, 2001 :23,24).

El gobierno francés a través de la cooperación francesa distribuye la ayuda en tres sectores: desarrollo económico y social, educación y capacitación, salud y nutrición, teniendo este último un financiamiento de 279 mil dólares (PN U D, 2001:30).

El objetivo principal de la cooperación al desarrollo de losPaíses Bajos es la reducción sostenible de la pobreza en sectores como la atención sanitaria, disponibilidad y calidad de la educación, progreso económico, comercio internacional. La distribución financiera para el sector salud y nutrición es de 152 mil dólares. (PNUD, 2001:31,32).

El gobierno del Japón persigue la seguridad humana, la protección de la vida. En 1999 la Cooperación Japonesa y el gobierno de $\mathrm{H}$ onduras se reunieron con el propósito de concertar las áreas prioritarias como la infraestructura, sal ud y saneamiento, agricultura, apoyo para la balanza de pagos y vivienda.- La distribución financiera estimada para el sector salud y nutrición es de 151, 488 mil dólares, representando el 11\% detotal del desembolso.(PN U D, 2001: 37,38).

El R eino U nido de la G ran Bretaña apoya los si guientes sectores: alivio de la deuda externa, infraestructura y telecomunicaciones, desarrollo económico y social, medio ambiente y salud y nutrición, siendo el apoyo para este último sector de 41,100 dólares (PNUD, $2001: 40$ ).

La Soberana O rden de M alta, el área temática de interés consiste en apoyar el desarrollo del sector salud, la cooperación se canaliza mediante donaciones de medicamentos, construcción de centros de salud y provisión de ropa de alimentos, la distribución financiera para el sector es de 600 mil dólares (PNU D, 2001 :41, 42).

Por su parte el gobierno de Suecia, debido a que Honduras es uno de los más pobres del continente y el que resultó más afectado por el huracán M itch ha orientado su cooperación a sectores sociales como: salud, agua y saneamiento, dándole prioridad a la población pobre; la cantidad estimada para el sector salud fue de 41800 mil dólares( PNUD, $2001: 43,44)$.

La C ooperación Suiza se concentra en cinco sectores: producción agrícola, fomento empresarial, agua y saneamiento, ayuda humanitaria, entorno macro económico.- Siendo la distribución financiera para el sector agua y saneamiento de 174,000 dólares (PN U D, 2001 :46,48).

La política de desarrollo de la U nión Europea se basa en el principio del desarrollo social y humano participativo en un marco sostenible y equitativo, las áreas prioritarias de la cooperación en $\mathrm{H}$ onduras son las siguientes: consolidación de la democracia, mejoramiento de la administración publica, inversión en capital humano los sectores de educación y salud, apoyo al desarrollo económico duradero y equitativo en el sector agrícola, protección del medio ambiente,-- La distribución financiera para el sector salud es de 24,739 mil dólares. (PN UD, 2001 :49,51).

\section{COOPERACION MULTILATERAL}

El Banco de Desarrollo Interamericano (BID) entre las prioridades actuales de financiamiento incluye: la equidad social y reducción de la pobreza, el medio ambiente, la modernización y la integración.

Del desembolso total estimado de 611, 500 millones de dólares, se destinaron al sector salud 36 millones de dólares, lo que representa el 5.8\% (PNUD, $2001: 72,73$ ). 
El Banco M undial orienta sus esfuerzos en las siguientes áreas: reforma financiera y administración publica, salud, educación, respuesta a crisis económicas y protección del medio ambiente.- Del desembolso total 561,320 millones de dólares, 35,400 millones corresponden al sector salud que equivale al 6.3\% ( PNU D, 2001 :75.76).

El Fondo de Población de las $\mathrm{N}$ aciones U nidas, brinda apoyo en las áreas de salud sexual y reproductiva, así como de población y de estrategias de desarrollo.- La asistencia de FN U A P en H onduras se enmarca en los siguientes problemas identificados. alta mortalidad materna, embarazo en adolescentes, VIH - SIDA, violencia basada en género.- La distribución financiera destinada para el sector salud es de, 41,456 mil dólares (PN U D, 2001 :87,89).

O NUSIDA, Programa de las Naciones U nidas, el cual es el principal impulsor de la acción mundial de la lucha contra el VIH SIDA, la distribución financiera estimada para el sector salud es de 215 mil dólares (PNU D, 2001:93, 94).

La O PS/O M S Organización Panamericana de la Salud, y O rganización M undial de la Salud).- La labor de la OPS en H onduras sobre la base de cinco grandes estrategias que son: prevención y control de enfermedades, salud en el desarrollo humano, programa especial de análisis en salud, protección y desarrollo del ambiente, desarrollo de sistemas y servicios de salud, la distribución financiera para el sector salud es de 51,899 mil dólares, lo que equivale al 51\%, pues el desembolso total es de 91,633 mil dólares.

El programa mundial de alimentos, durante y después del huracán $M$ itch, ha proporcionado asistencia al pueblo hondureño brindándole alimentos por trabajo, los sectores a los cuales se orienta este tipo de asistencia son: salud, medio ambiente educación, desarrollo económico y social, agricultura, la distribución financiera para el sector salud y nutrición es de 111,640 mil dólares(PN U D, 2001: 99,100).

Las áreas prioritarias para el PN U D en H onduras son: desarroIlo humano, equidad de género, gobernabilidad, desarrollo rural, medio ambiente, gestión de riesgo y SIDA siendo la distribución financiera estimada para el sector salud de 51,229 mil dólares(PN U D, $2001: 101,102)$.
U N ICEF (Fondo de las N aciones U nidas para la Infancia) este programa de cooperación en H onduras consta de cinco áreas: desarrollo del niño, salud y nutrición, agua y saneamiento, educación básica, equidad y género, la distribución financiera para el sector salud es de 502 mil dólares(PN U D, 2001 : 107,108).

\section{CONCLUSIONES}

- La disponibilidad de agua dulce a nivel mundial y nacional puede convertirse en un serio problema, cuando se vuelve escasa 0 cuando el aumento de la población sobrepasa la disponibilidad de recursos hídricos.

- Dada la importancia y la relación que existe entre los sectores de salud, agua y saneamiento en la vida de las personas ha motivado a la comunidad internacional a la realización de cumbres y conferencias para hacer conciencia tanto en los gobiernos como en sus poblaciones.

- El mejoramiento de la cobertura de los servicios de salud, agua y saneamiento, en $\mathrm{H}$ onduras se debe en gran medida a la cooperación financiera internacional, bilateral, multilateral y de país.

- Por la importancia que tiene para la población hondureña los servicios de agua y saneamiento, el gobierno ha legislado para lograr una mejor prestación, acceso y cobertura de estos servicios. 